\title{
Hibiscus sabdariffa L. extract: Characterization (FTIR-ATR), storage stability and food application
}

\author{
Carolina Moser Paraíso1*, Suelen Siqueira dos Santos ${ }^{1}$, Camilla Yara Langer Ogawa², Francielle Sato $^{3}$, \\ Onélia A. A. dos Santos ${ }^{4}$, Grasiele Scaramal Madrona ${ }^{5}$
}

${ }^{1}$ Graduate Program in Food Science, State University of Maringá, Avenida Colombo 5790, Maringá-PR, Brazil, ${ }^{2}$ Graduate Program in Physics, State University of Maringá, Avenida Colombo 5790, Maringá-PR, Brazil, ${ }^{3}$ Departament of Physic, State University of Maringá, Avenida Colombo 5790, Maringá-PR, Brazil, ${ }^{4}$ Departament of Chemical Engineering, State University of Maringá, Avenida Colombo 5790, Maringá-PR, Brazil, ${ }^{5}$ Department of Food Engineering, State University of Maringá, Avenida Colombo 5790, Maringá-PR, Brazil.

\section{A B S TR A C T}

The objective was to evaluate the extract stability of hibiscus in different conditions and the food application. Anthocyanins (TA), phenolic compounds (TP) and color, at: 4 and $25^{\circ} \mathrm{C}$, presence or absence of light, pH stability and FTIR were evaluated. Gelatin developed with hibiscus extract was submitted to sensory analysis. Light and temperature factors affected the stability of TP and TA throughout the storage. Higher stability was observed at $4{ }^{\circ} \mathrm{C}$ and absence of light (in relation to TA and TP respectively, $3 \%$ and $26 \%$ losses were observed in this condition against $43 \%$ and $39 \%$ at $25{ }^{\circ} \mathrm{C}$ with light). Regarding $\mathrm{pH}$, it was observed that $\mathrm{pH}$ change affected the absorbance and color in the hibiscus extract. Finally, the hibiscus extract, when added at the highest concentration into gelatin, was the most accepted by tastes, and scored 7 (like moderately) for color and global acceptance.

Keywords: FTIR; Gelatin; Antioxidant; Roselle

\section{INTRODUCTION}

Hibiscus sabdariffa L., also known as hibiscus or roselle, is an herbaceous plant of the genus Hibiscus, family Malvaceae, grown in tropical and subtropical environments. The calyces of hibiscus present high content of bioactive compounds, such as anthocyanins and other phenolic compounds responsible for their antioxidant properties (Cid-Ortega and Guerrero-Beltrán, 2015; Da-costa-rocha et al., 2014)

The major anthocyanins found in the calyx of hibiscus are delphinidin 3-O-sambubioside and cyanidin 3-O-sambubioside, with contents up to $0.75 \mathrm{mg} / \mathrm{mL}$ extract (Sinela et al., 2017). Research shows that anthocyanins have beneficial properties to human health, such as, antioxidant activity that can prevent oxidation of low-density lipoprotein cholesterol and reduce cholesterol, antihypertensive effect, prevention of cardiovascular and liver diseases, reduction of obesity and diabetes, and improve diuretic function (Nwachukwu et al., 2016; Guardiola and Mach, 2014).
Due to the importance of the different bioactive compounds present in hibiscus calyces, its extract appears as a potential source of these compounds for several applications, such as in food (Cid-Ortega and Guerrero-Beltrán, 2015). Anthocyanin-containing plant extracts can also be used as a substitute for synthetic dyes because of their bright color and water solubility and can be incorporated into food, thus increasing possible beneficial health effects (Pedro et al., 2016). However, the stability of anthocyanins depends on several chemical and environmental factors, such as temperature, $\mathrm{pH}$, light, oxygen, metal ions and enzymatic activity. Therefore, due to different environmental conditions during food processing and storage, the addition of these compounds in food products is still challenging (Mahdavi et al., 2016; Francis, 1989).

Analysing the literature a few studies report the use of hibiscus extract as a functional ingredient. A recent research evaluated the application of hibiscus extract in gelatin (in the same condictions used in this paper), and observed that in vitro digestion and colonic fermentation presented losses

\footnotetext{
*Corresponding author:

Aricléia de Moraes Catarino, Post-Graduation Program in Agriculture in the Humid Tropics, National Research Institute of the Amazon, Manaus, AM, Brazil. E-mail: amoraescatarino@gmail.com
} 
of phenolic compounds, anthocyanins and antioxidant activity of gelatin, being the hibiscus extract feasible for application in food products (Paraíso et al., 2019).

In this context, the present study aimed to evaluate the stability of hibiscus calyx extract against variations in temperature, light exposure and $\mathrm{pH}$. After that, the gelatin was chose as food matrix for application and evaluation.

\section{MATERIAL AND METHODS}

\section{Hibiscus calyx}

The hibiscus calyces were purchased in natura, from the same batch (harvest of 2016/2017) from a producer in Maringá, Paraná, Br (latitude:-23.4855, longitude: -51.7927). The calyces were sanitized (sodium hypochlorite solution $200 \mathrm{ppm}$ for $15 \mathrm{~min}$ ) and dried at $60^{\circ} \mathrm{C}$ for 22 hours in a forced air chamber. Then, the calyces were ground in an electric mill and classified according to granulometry using the Tyler sieves series. After preliminary tests, the material was chosen with an average diameter of $0.45 \mathrm{~mm}$ for conducting the experiments.

\section{Chemicals and reagents}

Folin-Ciocalteu reagent was obtained from Sigma-Aldrich Chemical Co. (St. Louis, MO, USA) and the other reagents used were of analytical grade. Distilled water was used in all trials.

\section{Hibiscus calyx extract}

Extraction of anthocyanins and phenolic compounds from hibiscus calyces was performed by ultrasonic assisted method. The samples were placed in an ultrasonic bath (Ultracleaner 1650 Unique, $40 \mathrm{KHz}$ frequency) at $60{ }^{\circ} \mathrm{C}$ for 45 minutes, ratio calyx: solvent of $1: 10$, using ethanol (25\% v/v) as solvent (Paraíso et al., 2019). The resulting extract was filtered on Whatman No. 4 filter paper, stored in the dark at $25^{\circ} \mathrm{C}$ and further analyzed. For food application, the extract was stirred at $65^{\circ} \mathrm{C}$ until total evaporation of the solvent and lyophilized (Shirahigue et al., 2011). The experiment was conducted in duplicate.

\section{Extract characterization (FTIR-ATR)}

A Fourier transform infrared spectrometer (Vertex $70 \mathrm{v}$, Bruker, Germany) coupled to an attenuated total reflectance accessory (Platinum, Bruker, Germany) was used to determine the phenolic compounds and anthocyanins present in the dried hibiscus calyx and the calyx extract. The sample was placed onto the diamond crystal, maintaining contact with the diamond throughout the measurement. Each spectrum was an average of 128 scans, with spectral resolution of $4 \mathrm{~cm}^{-1}$. The spectral measurement range was 4000 to $400 \mathrm{~cm}^{-1}$.
Extract stability under temperature and light conditions The extracts were evaluated for 22 days for temperature conditions of 4 and $25^{\circ} \mathrm{C}$, Light and No Light by using two fluorescent lamps of $20 \mathrm{~W}$ and a dark chamber, evaluating as a response total phenolic compounds, total anthocyanins and color, always in triplicate.

The determination of total phenolics (TP) was performed using the Folin-Ciocalteu assay, and results were expressed as $\mathrm{mg}$ of gallic acid equivalent (GAE). $\mathrm{g}^{-1}$ extract (Pierpoint, 2004; Singleton \& Rossi, 1965).

For the determination of total anthocyanin content (TA), a methodology described by (Lees and Francis, 1972) was used. The total anthocyanin content was expressed in mg equivalent of cyanidin-3-glucoside. $100 \mathrm{~g}^{-1}$ extract and calculated according to equation (1).

$$
\text { Total antocyanin }=\frac{\text { Ass snm } \times \text { dilution factor }}{98,2}
$$

The color $\left(\mathrm{L}^{*}, \mathrm{a} *\right.$ and $\left.\mathrm{b} *\right)$ was evaluated by means of a Konica Minolta ${ }^{\circledR}$ CR400 portable colorimeter, with integration sphere and angle of view of $3^{\circ}$. The system used was CIEL $* a * b *$. The angle $\mathrm{H}^{\circ}$ was calculated according to equation (2).

$$
b=\tan ^{-1}\left(\frac{b^{*}}{a^{*}}\right)
$$

\section{pH stability}

The extract was diluted with distilled water until an absorbance of 1.0 to $519 \mathrm{~nm}$ was reached. Aliquots of $\mathrm{KOH}\left(1 \mathrm{~mol} \mathrm{~L}^{-1}\right)$ were added to the extract and the spectrophotometer (UV-1800/Shimadzu ${ }^{\circledR}$ ) reading was performed between pHs 3 to 8 , at wavelengths of 800 to 400 nm (Pedro et al., 2016).

\section{Extract application in gelatin}

Gelatins were developed according to Akhavan et al. (2016), with modifications. After preliminary concentration tests, two samples were prepared (Table 1), with lyophilized extract concentrations of $2 \%(\mathrm{~F} 2)$ and $4 \%(\mathrm{~F} 4)$. To prepare the gelatin $625 \mathrm{~mL}$ of hot water were added to the ingredients. Gelatins were stored at $4{ }^{\circ} \mathrm{C}$ until sensory analysis.

Table 1: Gelatin formulations (w/w \%)

\begin{tabular}{lcc}
\hline Ingredients (\%) & F2 & F4 \\
\hline Gelatin & 15 & 15 \\
Extratc (powder) & 2 & 4 \\
Sugar & 75 & 75 \\
Flavor & 2,5 & 2,5 \\
Maltodextrin & 5,5 & 3,5 \\
\hline
\end{tabular}

Emir. J. Food Agric • Vol 32 • Issue 1 • 2020 
For sensory analysis, an acceptance test was applied using the nine points hedonic scale, being 1-I disliked extremely the 9-I like extremely (Morais et al., 2014). The formulations were evaluated for color, flavor and overall acceptance by a team of approximately 120 untrained tasters, but potential consumers. Samples of $20 \mathrm{~g}$ were presented in white disposable plastic containers encoded with random three-digit numbers.

An intent-to-buy test was also applied, with a three-point scale (would certainly buy, perhaps would buy, would not buy).

This project was approved by the Ethical Comity of State University of Maringá by CAAE number: 79765717.0.0000.0104.

\section{Statistic analysis}

The analysis were performed in triplicate and statistically evaluated by means of Analysis of Variance (ANOVA), compared by Tukey's test with a significance level of 5\% $(\mathrm{p} \leq 0.05)$ using the statistical program Sisvar 5.6.

\section{RESULTS AND DISCUSSION}

\section{Extract charaterization (FTIR-ATR)}

The dried hibiscus calyces and the calyx extract were characterized by FTIR-ATR spectroscopy (Figs. 1A and 1B, respectively) to determine possible bioactive compounds and potential for technological application in food. The main peaks observed in the two samples were: $\sim 1265 \mathrm{~cm}^{-1}$, attributed to the stretching of O-C acid groups (Johson et al., 2017). Peaks between 1100 and $1071 \mathrm{~cm}^{-1}$, indicate the presence of anthocyanins (cyanidin-3-O-sambubioside and delphinidin-3-O-sambubioside) showing the presence of these compounds in the samples (Choong et al., 2016). The region between 3100 and $3500 \mathrm{~cm}^{-1}$ is attributed to O-H stretch vibration (Lee et al., 2013). Peaks at 2919 and $\sim 2848 \mathrm{~cm}^{-1}$ refer to asymmetric and symmetrical stretching of $\mathrm{CH}_{2}$, respectively (Eltahir et al., 2014). In Fig. 1A, the peaks at $\sim 1783 \mathrm{~cm}^{-1}$ and Fig. $1 \mathrm{~B}$ at $\sim 1786 \mathrm{~cm}^{-1}$ are attributed to the stretching of $\mathrm{C}=\mathrm{O}$ (Lee et al., 2013; Pappas et al., 1998), while the pull of $\mathrm{C}=\mathrm{N}$ is assigned to the peak $\sim 1615 \mathrm{~cm}^{-1}$. The vibrational mode of angular deformation of $\mathrm{CH}_{3}$ was evidenced at peak $\sim 1364 \mathrm{~cm}^{-1}$. At $\sim 1185 \mathrm{~cm}^{-1}$ is the stretching of C-O-C and at $\sim 1031 \mathrm{~cm}^{-1}$ the stretching of C-O (Haddad et al., 2011; Singha et al., $2009)$. The $\sim 771 \mathrm{~cm}^{-1}$ peak refers to angular deformation of N-H (Johson et al., 2017).

\section{Extract stability in different temperature and light conditions}

Concentrations of TA in the hibiscus extract (Fig. 2) were not degraded at $4{ }^{\circ} \mathrm{C}$, but at $25{ }^{\circ} \mathrm{C}$ there was a $25 \%$ loss after the storage period (22 days). Phenolic compounds - TP (Fig. 2) showed a loss of $23 \%$ at $25^{\circ} \mathrm{C}$ and $15 \%$ at $4{ }^{\circ} \mathrm{C}$ after storage. It was expected because according the literature the most important factors affecting the stability of anthocyanins were temperature and storage time, and the higher the temperature and time, the higher the degradation of these compounds

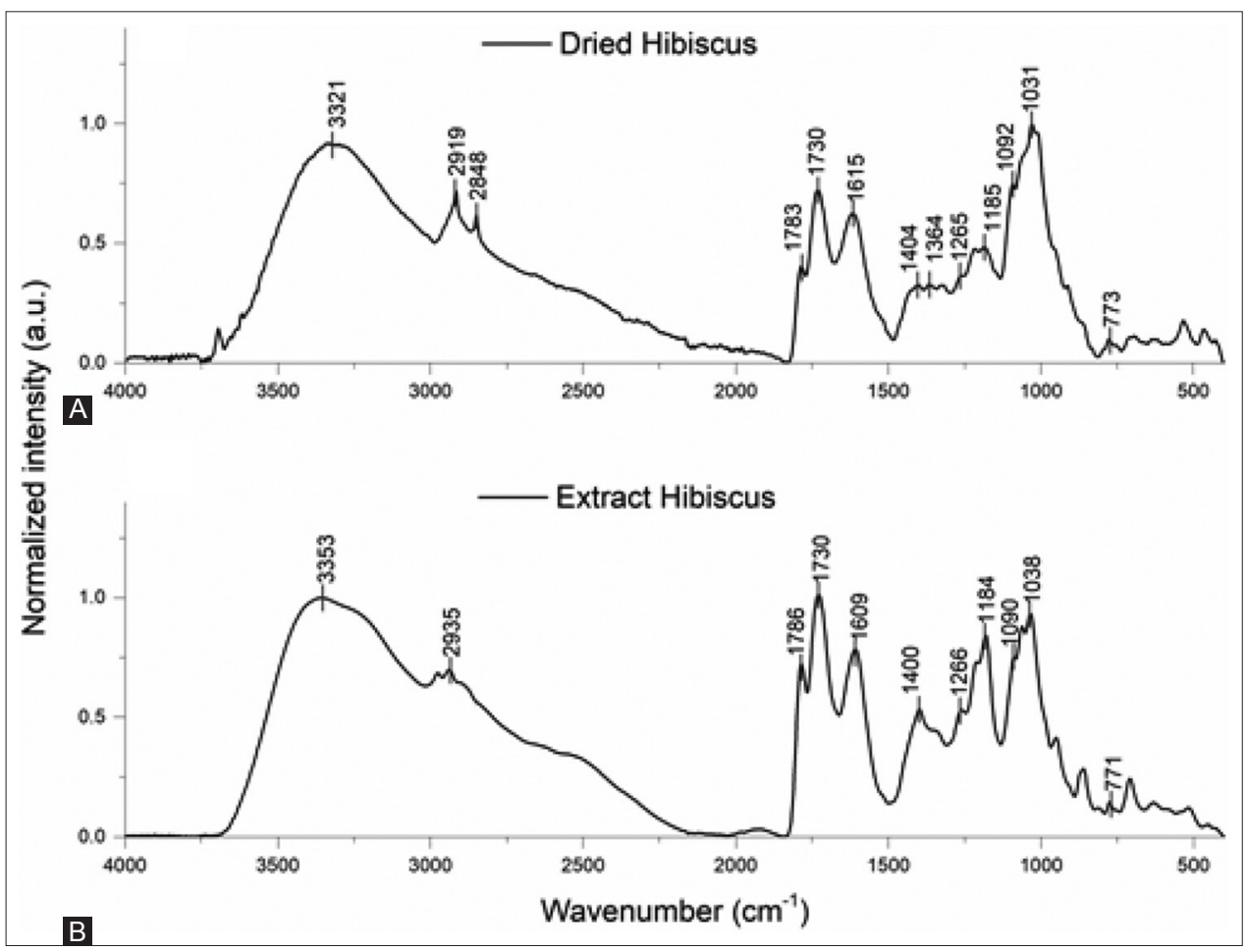

Fig 1. Spectrum FTIR-ATR: A- Dried hibiscus calyces and B- Hibiscus calyx extract. 


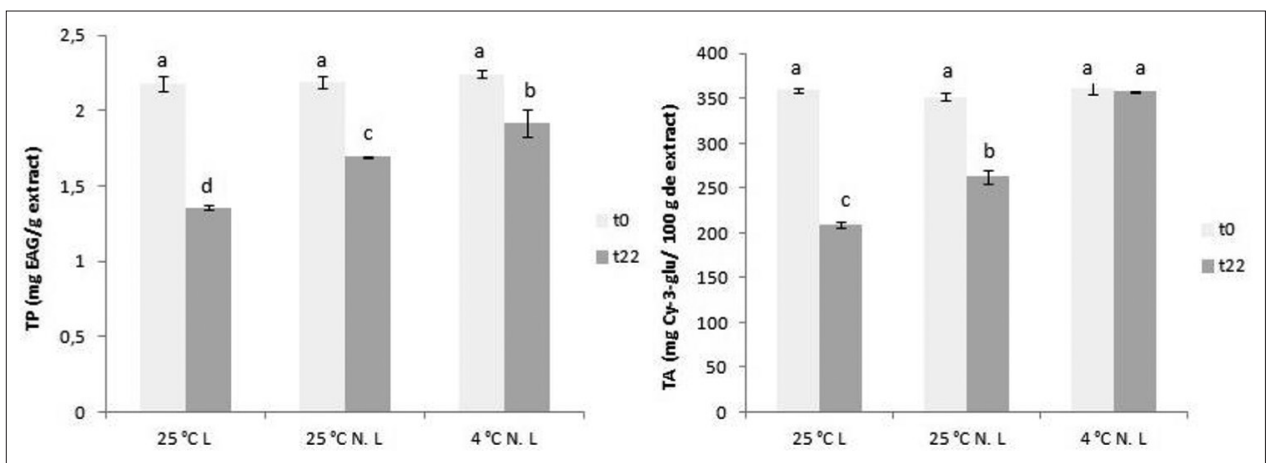

Fig 2. Extract Stability: TP and TA, 22 days of storage. TA= Total anthocyanin; TP=Total phenolic; L= Light; N.L= No Light.

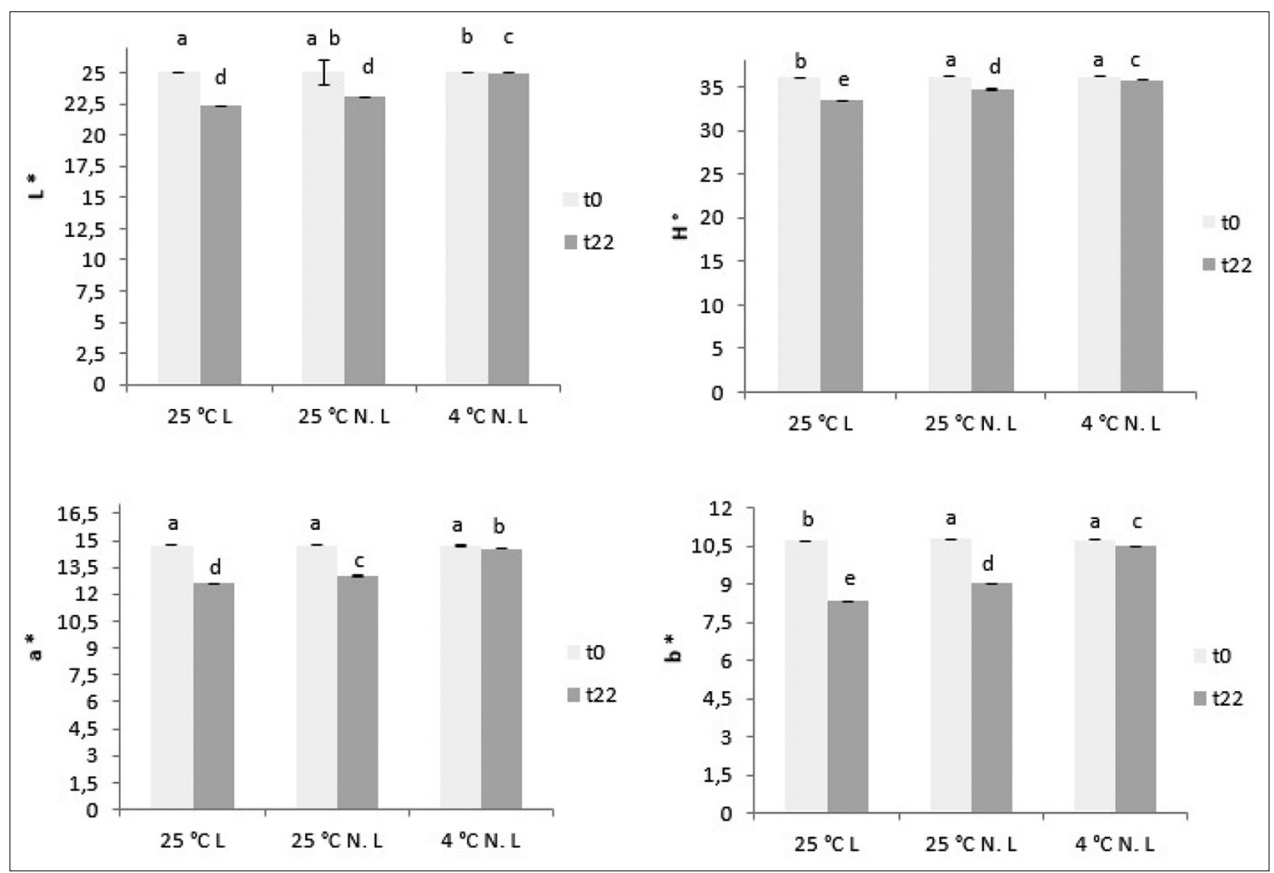

Fig 3. Extract Stability: Color $\left(L^{*}, a^{*}, b^{*}\right.$ e $\left.H^{\circ}\right)$ under light and temperature. $L=$ Light; N.L= No Light.

(Castañeda-Ovando et al., 2009). Previous studies have shown that with increasing temperature cyanidin and delphinidin cleavage occurs, thus forming degradation products such as protocatechic acid and gallic acid, respectively. In other studies, phloroglucinaldehyde has also been identified as a product of anthocyanin degradation (Kern et al., 2007; Sinela et al., 2017). Anthocyanin loss was already observed during storage of hibiscus extract, where concentrations decreased more rapidly at higher temperatures. After 60 days, $17 \%$ of the cyanidin 3-O-sambubioside was lost at $4{ }^{\circ} \mathrm{C}$ and $98 \%$ at $37^{\circ} \mathrm{C}$. For delphinidin 3-O-sambubioside this value was $11 \%$ and $99 \%$ at $4{ }^{\circ} \mathrm{C}$ and $37^{\circ} \mathrm{C}$, respectively (Sinela et al., 2017).

Light also affected stability of TA and TP in the hibiscus extract, as shown in Fig. 2. After exposure to fluorescent light at $25{ }^{\circ} \mathrm{C}$, the levels TA and TP decreased significantly. The concentrations of TA and TP, for extracts with light exposure, presented a loss of $41.95 \%$ and $38.02 \%$, respectively. As previously studied blackberry extracts stored in the dark presented greater stability in relation to the content of anthocyanins and antioxidant activity (Aramwit et al., 2010).

By evaluating extract coloration (Fig. 3), it was observed that for all parameters $\left(\mathrm{L}, \mathrm{a}^{*}, \mathrm{~b}^{*}\right.$ and $\left.\mathrm{H}^{\circ}\right)$ the loss was lower at $4{ }^{\circ} \mathrm{C}$. For the parameter luminosity $\left(\mathrm{L}^{*}\right)$, the loss was $0.2 \%$ at $4{ }^{\circ} \mathrm{C}$ and $8 \%$ at $25^{\circ} \mathrm{C}$, and for parameter $\mathrm{H}^{\circ}$ it was $1 \%$ and $4 \%$, at $4{ }^{\circ} \mathrm{C}$ and $25^{\circ} \mathrm{C}$, respectively. As reported in literature, the change in the color is correlated with TA degradation (Sinela et al., 2017), such fact can be observed in the present research (Fig. 2). Changes in the molecular structure of anthocyanins can occur at higher temperatures, favoring the formation of the chalcone structure. After the chemical ring is broken, there is further degradation, leading to loss of red coloration and formation of brown pigments (Cisse et al., 2012).

Light also affected the color of hibiscus extract, and for all parameters $\left(\mathrm{L}, \mathrm{a}^{*}, \mathrm{~b}^{*}\right.$ and $\left.\mathrm{H}^{\circ}\right)$ the loss was higher for the 
extract stored under light exposure. For the parameters a $*$ and $b^{*}$, a loss of $14 \%$ and $22 \%$, occurred respectively. Corroborating to this, a study carried out under the same storage conditions, showed a loss of $\mathrm{a} *$ and $\mathrm{b} *$ parameters for mulberry extract microcapsules stored in the presence of light (Santos et al., 2017).

\section{pH stability}

It is known that $\mathrm{pH}$ is one of the factors that most affects anthocyanin coloration and this is due to the ionic nature that allows reversible or irreversible changes in the structure of the molecule according to the prevailing $\mathrm{pH}$ (Cavalcanti et al., 2011; Pedro et al., 2016). Fig. 4 shows the behavior of anthocyanins in solution with increasing $\mathrm{pH}$. It was observed that hibiscus extract ( $\mathrm{pH}$ 2.6) had an absorbance $(\lambda \max )$ of $519 \mathrm{~nm}$ and intense red color, probably due to the high concentration of structural flavilium cations of anthocyanins (Fernandes et al., 2014). pH values between 3 and 5 , the $\lambda \max$ was also observed close to 519 , but a decrease in absorbance occurs, suggesting hydration of the flavilium cation, forming carbinol or pseudobase that reaches the equilibrium slowly with the colorless chalcone, thus decreasing the intensity of the red color until the solution turns colorless (Cavalcanti et al., 2011). As the $\mathrm{pH}$ increased to $8, \lambda \max$ shifted to $600 \mathrm{~nm}$ and the color of the extract changed to blue, due to the presence of the anhydrobase structural form. Studies on color stability of anthocyanins in relation to $\mathrm{pH}$ show that color variation is more significant in alkaline medium due to its instability (Castañeda-Ovando et al., 2009). The stability of anthocyanins is influenced mainly by the ring $B$ substituents and the presence of methoxy or hydroxyl groups, which decrease with the number of hydroxyl groups and increase with the number of hydroxyls (Hou et al., 2013). A similar study with purple sweet potato extract showed the same behavior of anthocyanins with increasing $\mathrm{pH}$, the $\lambda \max$ observed at acid pH was 530 and 610 at basic pH (He et al., 2015).

\section{Extract application in gelatin}

After obtaining the stability of hibiscus calyx extract, it was added into gelatin, that has a $\mathrm{pH}$ close to 4.1 and needs to be refrigerated, therefore these conditions result in better stability of the extract.

On sensory analysis, all attributes analyzed (color, flavor, overall acceptance) presented a significant difference ( $p<0.05)$ between the formulations (Table 2). The F4 formulation (4\% extract) received the highest score. In relation to the attributes global acceptance and color, the average score was 7 indicating "like moderately". This formulation had greater acceptability by the testers, possibly due to its more intense color (Fig. 5), and the higher concentration of hibiscus extract which has a red

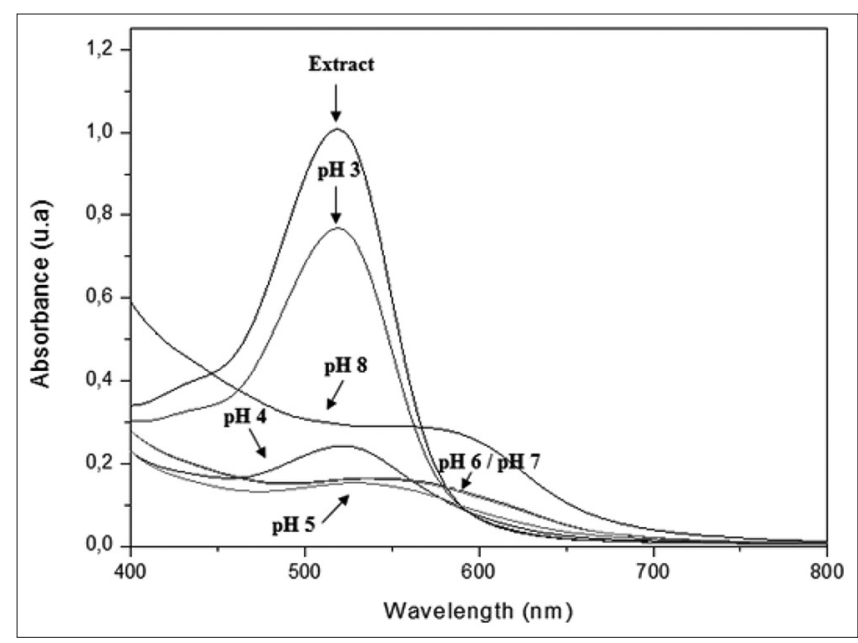

Fig 4. pH effect on anthocyanin absorbance in hibiscus calyx extract.

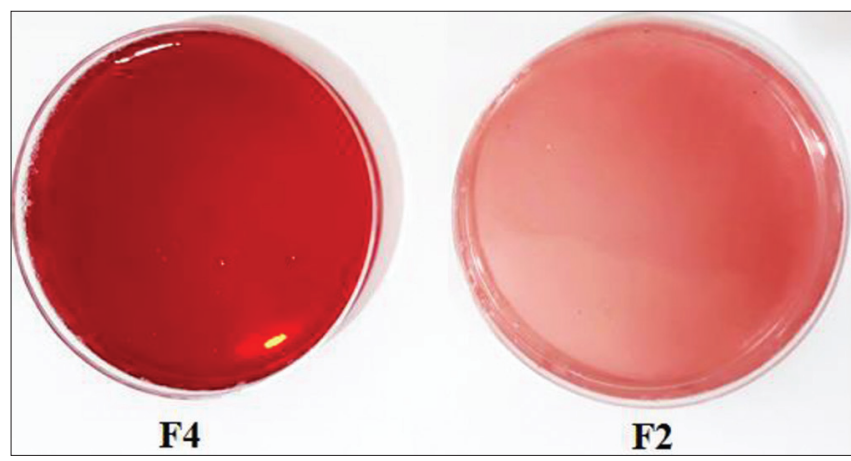

Fig 5. Gelatin with hibiscus calyx extract.

Table 2: Gelatin sensory analysis results

\begin{tabular}{lcc}
\hline Sensory attributes & \multicolumn{2}{c}{ Formulations } \\
\cline { 2 - 3 } & F2 & F4 \\
\hline Color & $5.66^{\mathrm{b}} \pm 1.56$ & $7.76^{\mathrm{a}} \pm 1.24$ \\
Flavor & $5.98^{\mathrm{b}} \pm 1.56$ & $6.54^{\mathrm{a}} \pm 1.48$ \\
Taste & $5.49^{\mathrm{b}} \pm 1.70$ & $6.40^{\mathrm{a}} \pm 1.71$ \\
Global acceptance & $5.87^{\mathrm{b}} \pm 1.46$ & $7.23^{\mathrm{a}} \pm 1.36$ \\
Intent of purchase & $1.63^{\mathrm{b}} \pm 0.59$ & $2.26^{\mathrm{a}} \pm 0.69$ \\
\hline
\end{tabular}

Averages with equal letters, in the same line, do not differ significantly at the $5 \%$ level of significance

coloration, and the high content of anthocyanins (CidOrtega and Guerrero-Beltrán, 2015). Color and appearance are key attributes for food quality, the first ones to be evaluated by consumers after purchase. The color also influences taste perception, and consumers relate specific colors to food quality (Damodaram et al., 2008; Sui et al., 2016). Therefore, it is evident that the color of the gelatin influenced its score, being this a decisive characteristic in the acceptance of the product. A previous study for the elaboration of a hibiscus drink by different industrial processes, observed that the drink containing more anthocyanins was better accepted by tasters in function of the stronger coloration, in addition to more acidity and flavor (Monteiro et al., 2017). 
When questioned about the intent of purchase, the tasters, on average, opted for "maybe would buy" for the F4 formulation and "would not buy" for the F2 formulation. F4 presents a higher concentration of extract, that is, a possible greater amount of bioactive compounds in its formulation, making this product interesting for consumers who are looking for healthy food that prevents oxidative stress (Ogundele et al., 2016).

\section{CONCLUSION}

Light and temperature factors affected the stability of phenolic compounds and anthocyanins throughout the storage under the different conditions studied, and greater stability was observed in samples stored at $4{ }^{\circ} \mathrm{C}$ and without light. The $\mathrm{pH}$ change affects the absorbance and color of anthocyanins in function of the ionic nature that allows changes in the structure of the molecule.

After the study of hibiscus extract stability, it was added into a food product. Gelatin sample with the highest extract concentration (4\%) was better accepted on sensory analysis.

Finally, the obtained extract is feasible to use by food industry, as a new ingredient or also as colorant, presenting good acceptance in the products and also the chain of antioxidant.

\section{ACKNOWLEDGEMENTS}

We acknowledge financial support from CAPES (Coordenação de Aperfeiçoamento de Pessoal de Nível Superior), and $\mathrm{CNPq}$ (Conselho Nacional de Desenvolvimento Científico e Tecnológico).

\section{Author's contributions}

Carolina Moser Paraíso: Conceptualization; Data curation; Formal analysis; Investigation; Methodology; Software; Roles/Writing - original draft; Writing - review \& editing. Suelen Siqueira dos Santos: Formal analysis; Investigation; Methodology; Roles/Writing - original draft; Writing - review \& editing. Camilla Yara Langer Ogawa: Formal analysis of FTIR; Methodology; Software; Roles/ Writing - original draft; Writing - review \& editing. Francielle Sato: Formal analysis of FTIR; Supervision; Visualization; Roles/Writing - original draft; Writing - review \& editing. Onélia A. A. dos Santos: Formal analysis; Supervision; Visualization; Roles/Writing - original draft; Writing - review \& editing. Grasiele Scaramal Madrona: Conceptualization; Data curation; Formal analysis; Funding acquisition; Investigation; Methodology; Project administration; Resources; Software; Supervision; Validation; Visualization; Roles/Writing - original draft; Writing - review \& editing.

\section{REFERENCES}

Aramwit, P., N. Bang and T. Srichana. 2010. The properties and stability of anthocyanins in mulberry fruits. Food Res. Int. 43: 1093-1097.

Castañeda-Ovando, A., M. D. L. Pacheco-hernández, M. E. PáezHernández, J. A. Rodríguez and C. A. Galán-vidal. 2009. Chemical studies of anthocyanins: A review. Food Chem. 113: 859-871.

Cavalcanti, R. N., D. T. Santos and M. A. A Meireles. 2011. Nonthermal stabilization mechanisms of anthocyanins in model and food systems-an overview. Food Res. Int. 44: 499-509.

Choong, Y., N. S. A. Yousof, M. I. Wasiman, J. A. Jamal and Z. Ismail. 2016. Determination of Effects of sample processing on Hibiscus sabdariffa L. Using tri-step infrared spectroscopy. J. Anal. Bioanal. Tech. 7: 1-9.

Cid-Ortega, S. and J. A. Guerrero-Beltrán. 2015. Roselle calyces (Hibiscus sabdariffa), an alternative to the food and beverages industries: A review. J. Food Sci. Technol. 52: 6859-6869.

Cisse, M., F. Vaillant, A. Kane, O. Ndiaye and M. Dornier. 2012. Impact of the extraction procedure on the kinetics of anthocyanin and colour degradation of roselle extracts during storage. J. Sci. Food Agric. 92: 1214-1221.

Da-costa-rocha, I., B. Bonnlaender, H. Sievers, I. Pischel and M. Heinrich. 2014. Hibiscus sabdariffa L. A phytochemical and pharmacological review. Food Chem. 165: 424-443.

Damodaram, S., K. Parkin and O. R. Fennema. 2008. Fennema's Food Chemistry. CRC Press, Boca Raton.

Eltahir, N. A., M. A. Siddig, A. A. Siddig and H. Adam. 2014. Structure and physical properties of flowering plants of the genus hibiscus. Sudan Med. Monit. 8: 135-139.

Fernandes, I., A. Faria, C. Calhau, V. de Freitas and N. Mateus. 2014. Bioavailability of anthocyanins and derivatives. J. Funct. Foods. 7: 54-66.

Francis, F. J. 1989. Food colorants: Anthocyanins. Crit. Ver. Food Sci. Nutr. 28: 273-314.

Guardiola, S. and N. Mach. 2014. Therapeutic potential of Hibiscus sabdariffa : A review of the scientific evidence. Endocrinol. Nutr. 61: 274-295.

Haddad, H. H., H. K. Mohammed, N. Abdul and K. Abdul. 2011. Synthesis, characterzation and analytical study of polymer derive from extracted (Hibiscus Sabdariffa) leaves plant with 8-hydroxyquinoline. J. Kerbala Univ. 9: 53-63.

He, X., X. Li, Y. Lv and Q. He. 2015. Composition and color stability of anthocyanin-based extract from purple sweet potato. Food Sci. Technol. 35: 468-473.

Hou, Z., P. Qin, Y. Zhang, S. Cui and G. Ren. 2013. Identification of anthocyanins isolated from black rice (Oryza sativa L.) and their degradation kinetics. Food Res. Int. 50: 691-697.

Johson, S., S. A. Razack, P. Sellaperumal, G. Ramakrishnan, P. Jayakrishnan, K. Sivanesan and R. Sahadevan. 2017. Antioxidant activity of iron isolated from petals of Hibiscus rosaSinensis. EC Microbiology. 7: 14-20.

Kern, M., D. Fridrich, J. Reichert, S. Skrbek, A. Nussher, S. Hofem, S. Vatter, G. Pahlke, C. Ruffer and D. Marko. 2007. Limited stability in cell culture medium and hydrogen peroxide formation affect the growth inhibitory properties of delphinidin and its degradation product gallic acid. Mol. Nutr. Food Res. 51: 1163-1172.

Lee, S. V., B. Vengadaesvaram, A. K. Arof and Z. H. Z. Abidin. 2013. Characterisation of poly (acrylamide-co-acrylic acid) mixed with anthocyanin pigment from Hibiscus sabdariffa L. Pigment Resin Technol. 42: 103-110. 
Lees, D. H. and F. J. Francis. 1972. Standardization of pigment analyses in cranberries. Hortscience. 7: 83-84.

Mahdavi, S. A., S. M. Jafari, E. Assadpour and M. Ghorbani. 2016. Storage stability of encapsulated barberry's anthocyanin and its application in jelly formulation. J. Food Eng. 181: 59-66.

Monteiro, M. J., A. I. Costa, G. Fliedel, M. Cissé, A. Bechoff, D. Pallet, K. Tomlis and M. M. Pintado. 2017. Chemical-sensory properties and consumer preference of hibiscus beverages produced by improved industrial processes. Food Chem. 225: 202-212.

Morais, E. C., A. R. Morais, A. G. Cruz and H. M. Bolini. 2014. Development of chocolate dairy dessert with addition of prebiotics and replacement of sucrose with different highintensity sweeteners. J. Dairy Sci. 97: 2600-2609.

Nwachukwu, D. C., E. I. Aneke, N. Z. Nwachukwu, N. Azubike and L. F. Obika. 2016. Does consumption of an aqueous extract of Hibiscus sabdariffa affect renal function in subjects with mild to moderate hypertension ? J. Physiol. Sci. 67: 227-234.

Ogundele, O. M. A., O. O. Awolu, A. A. Badejo, I. D. Nwachukwu and T. N. Fagbemi. 2016. Development of functional beverages from blends of Hibiscus sabdariffa extract and selected fruit juices for optimal antioxidant properties. Food Sci. Nutr. 4: 1-7.

Pappas, C., P. A. Tarantilis and M. Polissiou. 1998. Determination of Kenaf (Hibiscus cannabinus L.) lignin in crude plant material using diffuse reflectance infrared fourier transform spectroscopy. Appl. Spectrosc. 52: 1399-1402.

Paraíso, C. M., S. S. Santos, V. G. Correa, T. Magon, R. M. Peralta, J. V. Visentainer and G. S. Madrona. 2019. Ultrasound assisted extraction of hibiscus (Hibiscus sabdariffa L.) bioactive compounds for application as functional ingredient. J. Food Sci. Technol. 56: 4667-4677.
Pedro, A. C., D. Granato and N. D. Rosso. 2016. Extraction of anthocyanins and polyphenols from black rice (Oryza sativa L.) by modeling and assessing their reversibility and stability. Food Chem. 191: 12-20.

Pierpoint, W. S. 2004. The extraction of enzymes from plant tissues rich in phenolic compounds. Methods Mol. Biol. 244: 65-74.

Santos, S. S., L. M. Rodrigues, S. C. Costa, R. Bergamasco and G. S. Madrona. 2017. Microcapsules of blackberry pomace (Rubus fruticosus): Light and temperature stability. Chem. Eng. Trans. 57: 1837-1842.

Shirahigue, L. D., C. J. Contreras-Castillo, M. M. Selani, A. P. Nadai, G. B. Mourão and C. R. Gallo. 2011. Winery grape-residue extract: Effects on quality and sensory attributes of cooked chicken meat. Food Sci. Biotechnol. 20: 1257-1264.

Sinela, A., N. Rawat, C. Mertz, N. Achir, H. Fulcrand and M. Dornier. 2017. Anthocyanins degradation during storage of Hibiscus sabdariffa extract and evolution of its degradation products. Food Chem. 214: 234-241.

Singha, A. S., V. K. Thakur, I. K. Mehta, A. Shama, A. J. Khanna, R. K. Rana and A. K. Rana. 2009. Surface-modified Hibiscus sabdariffa fibers: Physicochemical, thermal, and morphological properties evaluation. Int. J. Polym. Anal. Charact. 14: 695-711.

Singleton, V. L. and J. A. Rossi. 1965. Colorimetry of total phenolics with phosphomolybdic-phosphotungstic acid reagents. Am. J. Enol. Vitic. 16: 144-158.

Sui, X., S. Bary and W. Zhou. 2016. Changes in the color, chemical stability and antioxidant capacity of thermally treated anthocyanin aqueous solution over storage. Food Chem. 192: 516-524. 